\title{
Stiffness of Fabrics Made by Open End Yarns
}

\author{
By A. R. Kalyanaraman
}

The South India Textile Research Association, Coimbatore-641 014, S. India

Based on the Journal of the Textile Machinery Society of Japan, Transactions, Vol. 39, No. 4, T1-T6 (1986-1)

\begin{abstract}
Open end yarns are structurally different in character from ring spun yarns. This difference in structure could affect the yarn properties and consequently the fabric properties. This paper attempts a comparison of the stiffness properties of open end yarn fabrics and similar ring spun yarn fabrics using the SITRA Electronic Stiffness Tester. The important conclusions are that although open end fabrics show a higher stiffness than similar ring spun fabrics, there are directions in which the stiffness of open end fabrics is lower. Also comparison has been made of the stiffness behaviour of a open end fabric pile with that of the ring spun fabric pile.
\end{abstract}

\section{Introduction}

Drape of fabrics is an essential property which decides the aesthetic appeal of a fabric and to a certain degree, it depends upon the resistance to bending of the fabric under its own weight. The resistance to bending is partly characterized in terms of the stiffness of the fabric. Therefore, the stiffness of fabrics is one of the important parameters that must be known in deciding the usefulness of a fabric. A fabric represents a two phase structure of air fibre where in each fibre is arranged parallel in a staggered manner with others of equal or unequal length and strength and is wound helically and twisted into a cylindrical structure called yarn. These cylinders are placed parallel to each other in a plane and are interlaced with similar structures orthogonally so as to form a fabric. Depending upon the fibre orientation and fabric geometry, such an arrangement brings in enormous possibilities in the property of the fabric.

Hearle $^{[1]}$ et al. have shown, that open end spun yarns are somewhat different in character from ring spun yarns and that the most basic structural differences are found in the fibre extent, fibre migration and fibre packing density. Also, they have shown that the fibre migration in an open end yarn is to be one-sixth of that in a typical ring spun yarn and this difference in structure is important in that it can affect the yarn properties. They have further concluded, that the open end yarns have lower fibre packing density than the corresponding ring spun yarns. Thus, these basic structural differences of the open end yarns may lead to change in its stiffness and consequently the drape of fabrics made of open end yarn may differ from the corresponding fabrics made out of similar ring spun yarns.

This paper is an attempt to study the bending nature of certain open end fabrics and compare the same with that of ring spun equivalents.

\section{Experimental}

The stiffness measurements have been made on SITRA Electronic Stiffness Meter which has been described elsewhere $^{[3]}$. The instrument is based on cantilever bending principle ${ }^{[3,4]}$. The fabric strip is made to advance on a smooth platform and is allowed to bend on its own weight under gravity at a horizontal straight edge. A parallel beam of white light is allowed to fall on a matrix of photodiodes kept on a vertical plane. Depending upon the stiffness, the fabric bends and obstructs the light beam. The photodiode response falls and gradually reaches a minimum. The length corresponding to the minimum current is reckoned as its stiffness value.

For comparison, five different fabrics made of ring spun yarn and five different fabrics made of open end spun yarn have been chosen. These fabrics have been made by yarns of nearly equal warp and weft counts, nearly equal ends and picks nearly equal thickness and nearly equal fabric weight so that for each fabric with open end yarn, there is a corresponding fabric with ring spun yarn.

The ends and picks of the fabrics have been measured using a count glass and an average of 10 such observation is taken and entered into the Table 1 for each fabric. The warp and weft yarn counts were estimated by removing 
Table 1 Physical properties of open end fabrics used and nearly similar ring spun fabrics

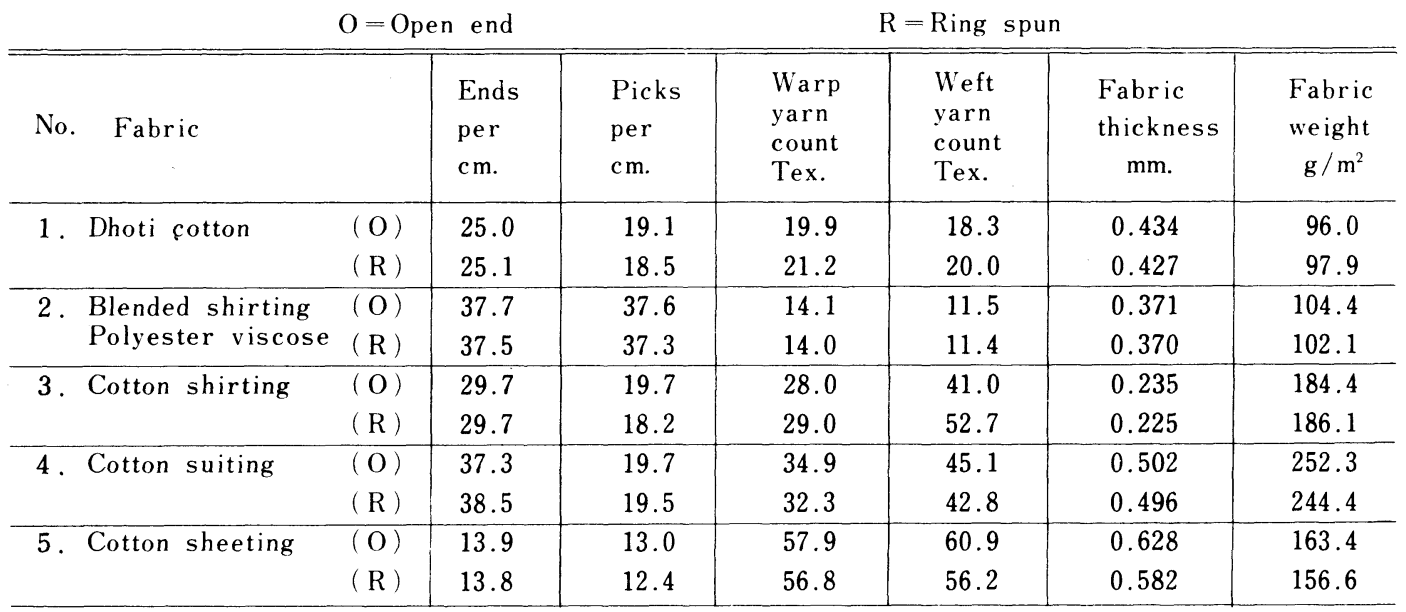

Table 2 Drape coefficient FRL drape meter

\begin{tabular}{c|c|c|c}
\hline \multirow{2}{*}{$\begin{array}{l}\text { Fabric } \\
\text { No. }\end{array}$} & \multicolumn{2}{|c|}{ Drape Coefficient } & $\begin{array}{l}\text { Ratio } \\
\text { Open end } \\
\text { Ring spun }\end{array}$ \\
\cline { 2 - 4 } & Ring spun & Open end & 1.052 \\
1. & 0.675 & 0.711 & 1.025 \\
2. & 0.800 & 0.820 & 1.032 \\
3. & 0.620 & 0.640 & 1.093 \\
4. & 0.640 & 0.700 & 1.010 \\
\hline 5. & 0.708 & 0.715 & \\
\hline
\end{tabular}

threads from the fabric and the straightened length of the yarn is taken after applying a tension of $0.75 \mathrm{~g} / \mathrm{unit}$ tex. 40 $\mathrm{cm}$ of this length is taken in each warp and weft direction and 10 such specimens are measured for each warp and weft and their mass is estimated under the standard atmosphere of testing. Linear density was calculated using the above observations and a mean of ten readings has been entered into the Table 1. Fabric thickness is estimated using dial gauge type thickness tester with the presser base area of $72.7 \mathrm{~mm}$. A mean of twenty observations is entered into the Table.

Fabric weight per unit area is estimated by weighing a conditioned specimen of area of $0.0645 \mathrm{~m}^{2}$ (avoiding selvedges) and the weight per $\mathrm{g} / \mathrm{unit}$ area is expressed as $\mathrm{g} / \mathrm{sq}$. meter by making ten observations.

The drape coefficient of each fabric was estimated using the FRL drape meter, plotting the contour of the shadow and by weighing method. Five samples are used for each observation and the experiments are repeated on both sides of the fabric. The average is entered into the Table 2.

Fabric strips of $25 \mathrm{~mm} \times 200 \mathrm{~mm}$ are cut and they are allowed to bend at a straight edge. When the bending fabric completely obstructs the parallel beam of light, the sensor output current reaches a minimum and the length of fabric corresponding to this minimum is noted. The experimental procedure is well described in earlier papers $^{[2,3,4]}$ and for each fabric, the average of twenty different reading is taken.

Now, the fabric strips are placed one over the other and the stiffness behaviour of the pile is studied. Fabric strips of dimensions $25 \mathrm{~mm} \times 200 \mathrm{~mm}$ are chosen and they are cut parallel to the warp direction and carefully placed one over the other and the observations are made. For each case, the experiment is repeated on 5 piles of similar composition and observations are made till the pile has attained a population of seven fabrics. The observations have been stopped here since seven layers of fabrics are sufficient enough to predict the bending behaviour of the pile. The results are in Table 3 .

Now, fabric strips of the specific dimensions are cut along the warp directions and at $15^{\circ}, 30^{\circ}, 45^{\circ}, 60^{\circ}, 75^{\circ}$ and $90^{\circ}$ to the warp and the stiffness behaviour in these directions are also measured as described previously. All experiments were conducted at $65 \%$ relative humidity and at a temperature of $72^{\circ}$ Fahrenheit.

Table 3 Stiffness and number of over-laps Fabric No. 1

\begin{tabular}{rl|c|c} 
& No. & Ring spun* & Open end spun* \\
\hline 1. & 2.40 & 2.60 \\
2. & 2.60 & 2.80 \\
3. & 2.95 & 3.13 \\
4. & 3.22 & 3.26 \\
5. & 3.40 & 3.35 \\
& 6. & 3.40 & 3.60 \\
Fabric No. 3 & 3.58 & 3.65 \\
& & & \\
& 1. & 2.45 & 3.02 \\
2. & 2.60 & 3.40 \\
3. & 2.74 & 3.56 \\
4. & 2.68 & 4.00 \\
5. & 2.80 & 4.05 \\
6. & 2.85 & 4.10 \\
7. & 2.96 & 4.30 \\
Fabric No. 5 & & \\
& 1. & 2.26 & 2.32 \\
2. & 3.20 & 3.30 \\
3. & 3.50 & 4.10 \\
4. & 3.70 & 4.24 \\
5. & 4.00 & 4.40 \\
6. & 4.30 & 4.80 \\
7. & 4.40 & 4.90 \\
\hline
\end{tabular}

*In both, same scale is used but arbitrary. 


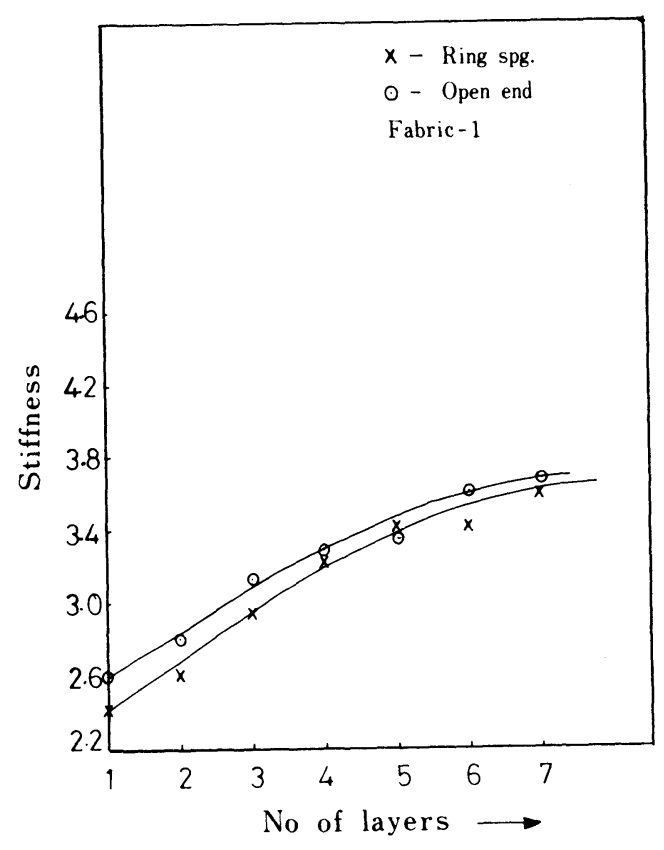

(a)

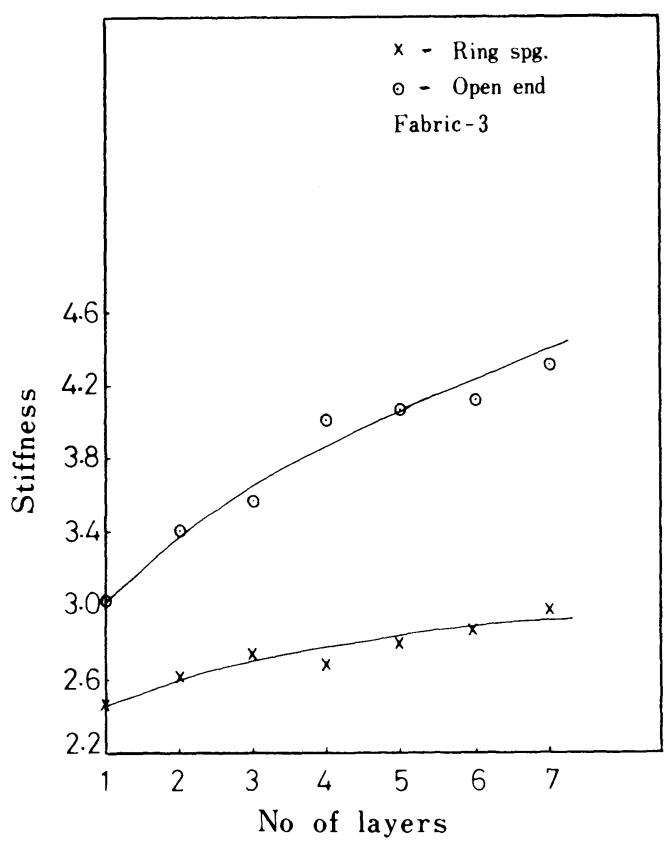

(b)

Fig. 1 The increase in layers vs. the stiffness of the pile

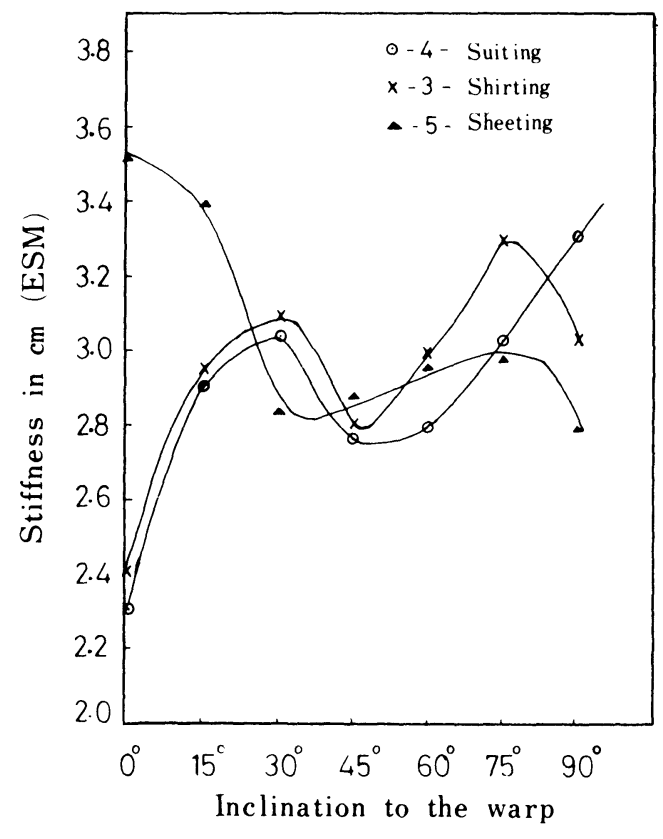

Fig. 2 The directional stiffness of the open end fabrics

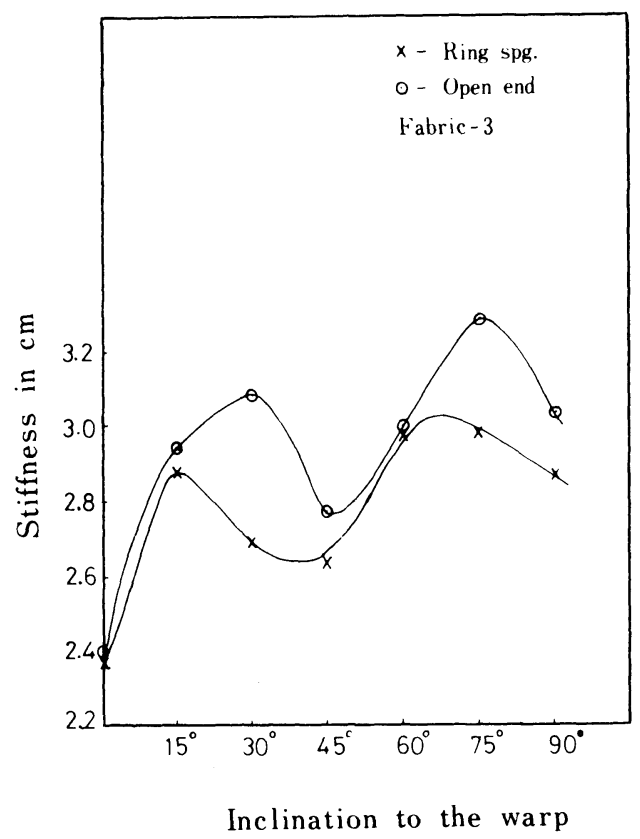

(b) 


\section{Discussion}

The physical properties of the fabrics are presented in Table 1 . One can easily note that in each case, the physical properties of open end fabrics are almost identical to that of the ring spun fabrics so as to study the effect of the open end process on the stiffness of fabrics. Although such studies on open end yarn has been known in the literature, this study highlights the same on fabrics. Table 2 gives the FRL drape coefficient for the ring spun fabrics and open end fabrics. It is clear that the open end fabrics show a higher drape factor signifying thereby that the open end fabric is stiffer. The relative stiffness factor namely the ratio of the stiffness of open end fabrics to that of ring spun fabric is given in the column 3 for Table 2 . It is seen that in all the cases the ratio is more one.

Table 3 gives the stiffness of the pile of fabrics. Both the piles have the same tendency namely they describe a parabola type of bending as the pile builds up. Whereas in the case of fabric 1 , the ring spun fabric pile almost bends like the open end fabric and the parabolas are very close to each other, for fabric 3 , the parabolas are quite markedly different. This is quite markedly seen in Figs. la and $1 b$.

Fig. 2 represents, the bending behaviour of the open end fabrics in directions inclined to the warp. On comparison with ring spun fabrics, the relative variation in the directional stiffness is very high and in the case of suiting, the stiffness in a particular direction is smaller than a similar ring spun fabric. The details can be seen in Table 4, where the ratio of the stiffness of open end fabrics to that of ring spun fabric is also given (Figs. $3 a, b$ and $c$ ). Although the open end fabric appears to be more stiff than the corresponding ring spun fabric, as per FRL drape meter, this study reveals that by choosing proper directions, the stiffness of open end fabrics could be reduced. This is a point of interest for garment designers and fabric users.

Peirce ${ }^{[5]}$ has described a formula to predict the stiffness in any direction of the fabric knowing the stiffness values along the warp and weft directions. If $C 1$ and $C 2$ are the stiffness values along warp and weft directions, the stiffness value $C$ along the direction $\alpha$ to the warp is given by

$$
\begin{aligned}
& C=C 1\left(\cos ^{2} \alpha+K^{2} \sin ^{2} \alpha\right)^{-2 / 3} \text { where } \\
& K=(C 1 / C 2)^{3 / 4}
\end{aligned}
$$

The calculated $C$ values are in Table 4 and also plotted in Figs. $4 \mathrm{a}$ and $4 \mathrm{~b}$. They do not seem to agree well as has been pointed out earlier for ring spun fabrics ${ }^{[2]}$.

Table 4 Stiffness at different inclination of ring spun $(\mathrm{R})$ and open end fabrics $(\mathrm{O})$ of similar properties, Their ratio( $r)$ and comparison of measured and calculated stiffness of open

\begin{tabular}{|c|c|c|c|c|c|c|c|}
\hline $\begin{array}{l}\text { Inclinstion } \\
\text { to the warp }\end{array}$ & & & $\begin{array}{l}\text { Fabric } \\
\text { No. } 1\end{array}$ & $\begin{array}{l}\text { Fabric } \\
\text { No. } 2\end{array}$ & $\begin{array}{l}\text { Fabric } \\
\text { No. } 3\end{array}$ & $\begin{array}{l}\text { Fabric } \\
\text { No. } 4\end{array}$ & $\begin{array}{l}\text { Fabric } \\
\text { No. } 5\end{array}$ \\
\hline \multirow[t]{4}{*}{0} & R ) & & 2.68 & 2.69 & 2.36 & 2.67 & 2.90 \\
\hline & r) & & 1.332 & 1.015 & 1.013 & 0.861 & 1.190 \\
\hline & $\mathrm{O}$ & Mes.) & 3.57 & 2.73 & 2.39 & 2.30 & 3.45 \\
\hline & $\mathrm{O}$ & Cal.) & - & - & - & - & - \\
\hline \multirow[t]{4}{*}{15} & R) & & 3.39 & 3.06 & 2.88 & 2.81 & 3.06 \\
\hline & r) & & 1.132 & 0.990 & 1.021 & 1.046 & 1.108 \\
\hline & $\mathrm{O}$ & Mes.) & 3.84 & 3.03 & 2.94 & 2.94 & 3.39 \\
\hline & $\mathrm{O}$ & Cal.) & 3.59 & 2.71 & 2.42 & 2.34 & 3.39 \\
\hline \multirow[t]{4}{*}{30} & R) & & 3.23 & 2.65 & 2.67 & 2.62 & 3.00 \\
\hline & r) & & 1.213 & 1.098 & 1.154 & 1.156 & 0.947 \\
\hline & $\mathrm{O}$ & Mes.) & 4.08 & 2.91 & 3.08 & 3.03 & 2.84 \\
\hline & $\mathrm{O}$ & Cal.) & 3.66 & 2.67 & 2.52 & 2.47 & 3.25 \\
\hline \multirow[t]{4}{*}{45} & R) & & 3.05 & 2.59 & 2.64 & 2.89 & 3.08 \\
\hline & r) & & 1.377 & 1.124 & 1.045 & 0.955 & 0.935 \\
\hline & $\mathrm{O}$ & Mes.) & 4.20 & 2.91 & 2.76 & 2.76 & 2.88 \\
\hline & $\mathrm{O}$ & Cal.) & 3.75 & 2.61 & 2.66 & 2.69 & 3.07 \\
\hline \multirow[t]{4}{*}{60} & R) & & 2.75 & 2.63 & 2.99 & 2.99 & 3.10 \\
\hline & r) & & 1.200 & 1.160 & 1.000 & 0.933 & 1.051 \\
\hline & $\mathrm{O}$ & Mes.) & 3.30 & 3.05 & 2.99 & 2.79 & 2.95 \\
\hline & $\mathrm{O}$ & Cal.) & 3.85 & 2.56 & 2.83 & 2.95 & 2.92 \\
\hline \multirow[t]{4}{*}{75} & R) & & 3.18 & 2.64 & 2.98 & 2.86 & 2.98 \\
\hline & r) & & 1.031 & 1.057 & 1.104 & 1.059 & 0.997 \\
\hline & $\mathrm{O}$ & Mes.) & 3.28 & 2.79 & 3.29 & 3.03 & 2.97 \\
\hline & $\mathrm{O}$ & Cal. ) & 3.93 & 2.52 & 2.97 & 3.19 & 2.82 \\
\hline \multirow[t]{4}{*}{90} & R ) & & 2.79 & 2.49 & 2.86 & 2.39 & 2.90 \\
\hline & r) & & 1.419 & 1.008 & 1.059 & 1.377 & 0.959 \\
\hline & $\mathrm{O}$ & Mes.) & 3.96 & 2.51 & 3.03 & 3.29 & 2.78 \\
\hline & $\mathrm{O}$ & Cal. ) & - & - & - & - & - \\
\hline
\end{tabular}
end fabrics-stiffness in CM. 


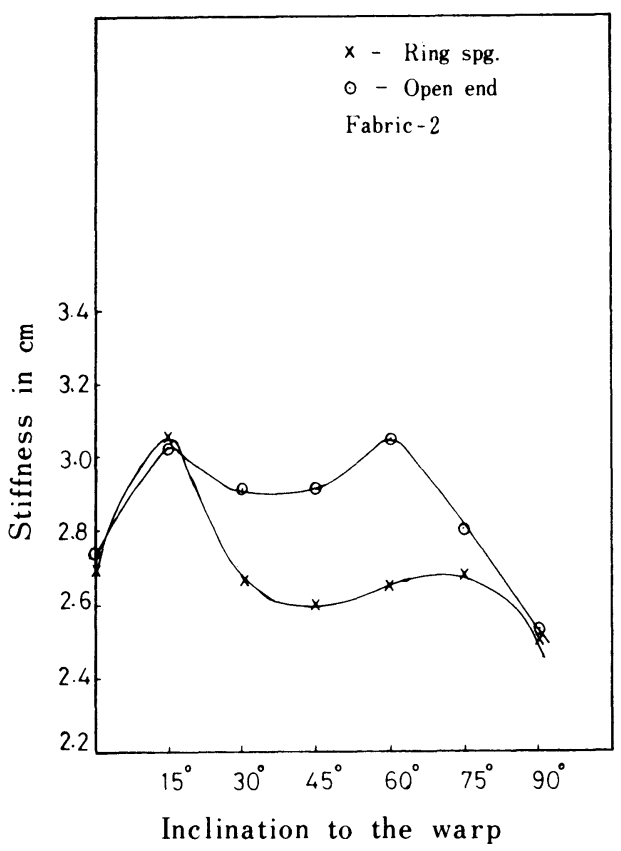

(a)

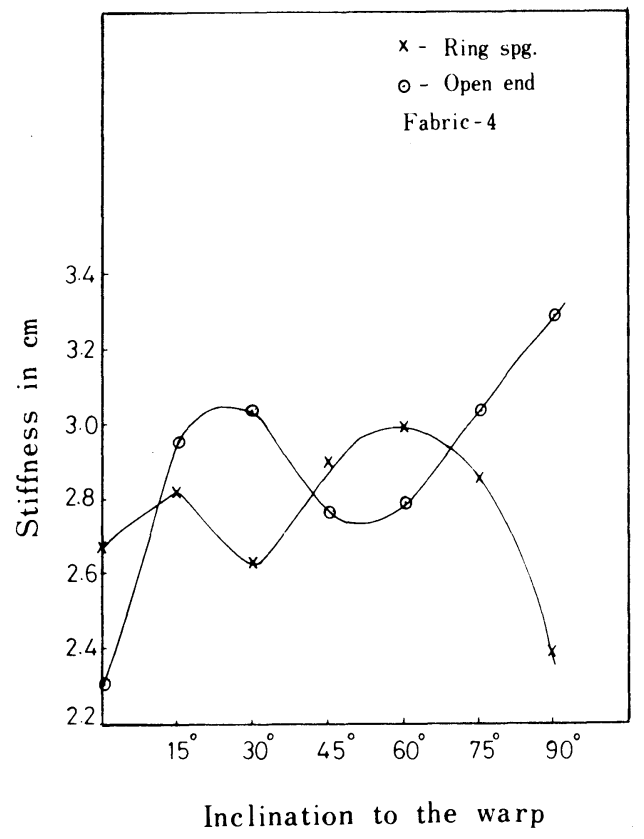

(c)

Fig. 3 Comparison of the directional stiffness of open end yarn fabrics and the ring spun yarn fabrics

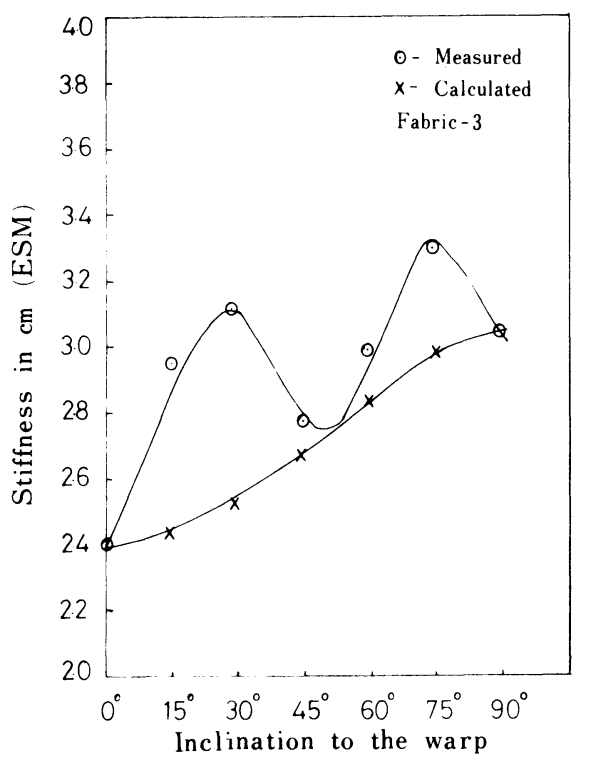

(a)

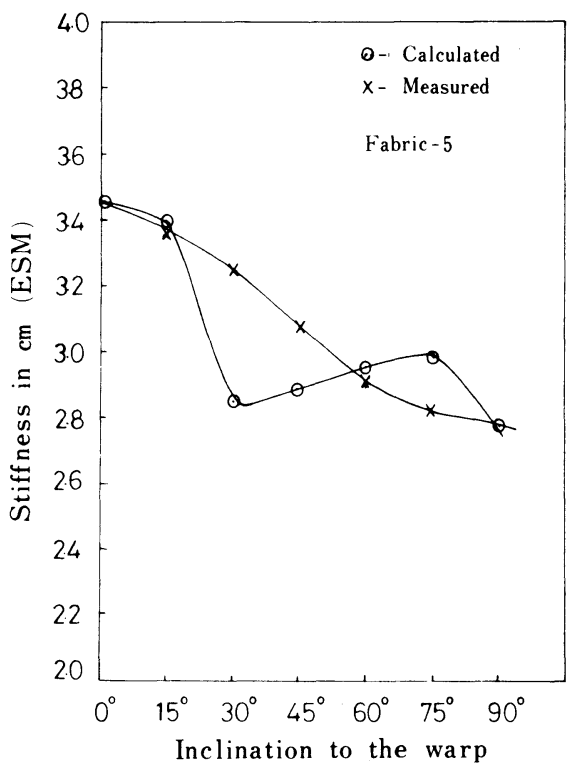

(b)

Fig. 4 The comparison of the measured directional stiffness of the open end fabrics and the calculated stiffness values.

\section{Conclusions}

1) FRL drape meter shows that open end fabrics are more stiff than the corresponding ring spun fabrics.

2) There are directions in open end fabrics where the stiffness is much smaller than the corresponding ring spun fabrics.

3) There are large fluctuations in the stiffness with direction. In other words, stiffness is a property which appears to be highly directional for a particular fabric.

4) The open end fabric pile is more stiffer than the corresponding ring spun fabric pile.
5) The calculated value of stiffness using Peirce's formula does not agree with the measured stiffness.

\section{Acknowledgement}

The author thanks Mr. A. Sivaramakrishnan for the collection of data. The encouragement and support given by $\mathrm{Mr}$. T. V. Ratnam, Director, SITRA is gratefully acknowledged. 


\section{Literature Cited}

[] Hearle, J. W. S., Lord, P. R. and Senturk, N., Fibre Migration in Open End Spun Yarns, J. Text. Inst., 63, 605-617 (1982).

[2] Kalyanaraman, A. R., Directional Stiffness of Fabrics and Fabric Piles (Under Publication).

[3] Kalyanaraman, A. R., and Sivaramakrishnan, A., An Electronic Instrument to Measure Stiffness Fabrics,
Text. Res. J., 53, 573-575 (1983).

[4] Kalyanaraman, A. R., and Sivaramakrishnan, A., An Electronic Fabric Stiffness Meter-Performance Evaluation with the known Instruments, Text. Res.J., 54, 479484 (1984).

[5] Peirce, F. T., The Handle of Cloth as a Measurable Quantity, J. Text. Inst., 21, 377-416 (1930). 